\title{
Global Outbreaks of SARS-nCoV-2 (COVID-19 Pandemic) and Spread out in Bangladesh
}

\author{
Md. Belal Hossain
}

Professor, Molecular Biology and Plant Virology Laboratory, Department of Plant Pathology, Sher-E-Bangla Agricultural University, Dhaka, Bangladesh

[Received: 17 April 2020; Accepted: 12 May 2020; Published: 1 June 2020]

\begin{abstract}
Currently, the world is concerned about the 2019 novel CoV (SARS-nCoV-2), the disease it causes has bee named "coronavirus disease 2019" (COVID-19) that was initially identified in Wuhan, China on 31 Decembe 2019. Infected patients presented with severe viral pneumonia and respiratory illness. The new SARS-CoV-2 i RNA genomes and a beta-coronavirus, like SARS-CoV and MERS-CoV. In this article, provide a brief insight into past and present outbreaks of COVID-19. At end of the April 2020, COVID-19 Pandemic spread out al over the world in 210 countries/areas and the number of confirmed cases has been mounting globally. Reporte in USA alone, over one million people are infected which is one-third of world confirmed cases and deaths case also near to one-fourth of the total estimated deaths cases so far recorded globally. In other countries of th world situation is almost same but in Europe COVID-19 positive cases so high including death cases. I Bangladesh, the number of confirmed cases and fatality rate is lower than other reported countries in the world due to deficient testing facilities and inadequate number of samples are tested, the virus seems to be highl. contagious in Bangladesh as well. Although the fatality rate of SARS-nCoV-2 is currently lower than SARS $\mathrm{CoV}$ and MERS-CoV, but the virus seems to be highly contagious based on the number of infected cases $\mathrm{t}$ date. [Bangladesh Journal of Infectious Diseases, June 2020;7(1):38-41]
\end{abstract}

Keywords: Infectious disease; coronavirus; SARS-nCoV-2; COVID-19 Pandemic; Bangladesh

Correspondence: Dr. Md. Belal Hossain, Professor, Molecular Biology and Plant Virology Laboratory, Department of Plant Pathology, Sher-E-Bangla Agricultural University, Sher-E-Bangla Nagar, Dhaka-1207, Bangladesh; Email: dr.mbhossain@sau.edu.bd; Cell No.: +8801711988444

Conflict of interest: Author has declare that there is no conflict of interests.

Funding agency: The study was not funded by any authority.

Contribution to authors: Md. Belal Hossain has involved in literature search, preparation and revision of this manuscript.

How to cite this article: Hossain MB. Global Outbreaks of SARS-nCoV-2 (COVID-19 Pandemic) and Spread out in Bangladesh. Bangladesh J Infect Dis 2020;7(1):38-41

Copyright: $\odot 2020$. Hossain. Published by Bangladesh Journal of Infectious Diseases. This article is published under the Creative Commons CC BY-NC License (https://creativecommons.org/licenses/by-nc/4.0/). This license permits use, distribution and reproduction in any medium, provided the original work is properly cited, and is not used for commercial purposes.

\section{Introduction}

"Virus" is from the Greek word meaning for "poison" and it was initially described by Edward Jenner in $1798^{1}$. According to Edward Jenner, a virus is a package of genetic information protected by a protein shell for delivery into a host cell to be expressed and replicated. The most acceptable and familiar definition of virus, "A virus is a small, infectious, obligate intracellular parasite, highly host specific, 
capable of replicating itself in a host cell". Coronaviruses $(\mathrm{CoV})$ under the order Nidovirales, family Coronaviridae, and subfamily Coronavirinae are enveloped viruses with unusually large plusstrand RNA genomes of 26 to $32 \mathrm{~kb}^{2}$. Coronaviruses are a large family of viruses that causes serious respiratory illnesses. They are common in different species of animals, including camels, cattle, cats, bats and also in humans ${ }^{3}$. Animal coronaviruses can infect to humans and then spread among the people such as with SARS-COV, MERS-COV and now with the newly reported coronavirus. The outbreak was first observed on December 31, 2019 in Wuhan, China. The virus has been named "SARS-COV-2" and the disease it causes has been named "coronavirus disease 2019" (abbreviated "COVID-19"). The CoV are subdivided into four genera, alpha, beta, gamma and delta $^{4}$. The SARS-CoV-2 virus is a beta-coronavirus, like SARS-CoV and MERS-CoV. All three of these viruses have their origins in 2019-nCOV emerged in a seafood and poultry market in the Chinese city of Wuhan in 2019. COVID-19 cases have been detected in all countries of the world and the World Health Organization (WHO) characterized the severe outbreak as a pandemic on 11 March, 20205. Humanto-human transmission occurs through close contact and most of the people get infected with human strains of coronaviruses at some point in their lives. Human coronaviruses can cause other illnesses, such as pneumonia or bronchitis. This is more common in individuals with heart and lung disease, those with weakened immune systems, infants, and older adults.

\section{Global outbreaks of SARS-nCoV-2 (COVID-19)}

The new type coronavirus (SARS-nCoV-2) were first reported in Wuhan, a city with a population of around 11 million and the capital of Hubei province, China, in December 20019. On 12 January, 2020 China shared the genetic sequence of the novel coronavirus. Thailand reported the first confirmed case of the novel coronavirus outside China on 13 January, 2020. After a few days, on 20 January USA reported its first confirmed case, in someone who had returned to Washington State on $15^{\text {th }}$ January after visiting family in Wuhan, China. The first reported case in Europe was in France on $24^{\text {th }}$ January; $28^{\text {th }}$ February Nigeria reported the first case of COVID-19 in Sub-Saharan Africa. After that it was spread in most of the countries in the world and On March 11, 2020, the World Health Organization declared the COVID-19 outbreak a pandemic ${ }^{5}$. On 21 April 2020, Globally, approximately 24,48,000 confirmed cases of coronavirus disease 2019 (COVID-19) caused by SARS-nCoV-2 have been reported, including an estimated 1,70,000 deaths in 218 countries/areas. The activity levels of SARS-nCoV-2 (COVID-19) are showed different in the different parts of the world. Data from China have indicated that older adults, particularly those with serious underlying health conditions, are at higher risk for severe COVID-19associated illness and death than are younger persons.

Although the majority of reported COVID-19 cases in China were mild ( $81 \%$ ), approximately $80 \%$ of deaths occurred among adults aged $\geq 60$ years; only one $(0.1 \%)$ death occurred in a person aged $\leq 19$ years. In this report, COVID-19 cases in the United States that occurred during 12 February 16 March, 2020 and severity of disease (hospitalization, admission to intensive care unit [ICU], and death) were analyzed fatality rate by age group and sex (Figure I). As of March 16, a total of 4,226 COVID-19 cases in the United States had been reported to CDC, with multiple cases reported among older adults living in long-term care facilities. Overall, $31.0 \%$ of cases, $45.0 \%$ of hospitalizations, $53.0 \%$ of ICU admissions, and $80.0 \%$ of deaths associated with COVID-19 were among adults aged $\geq 65$ years with the highest percentage of severe outcomes among persons aged $\geq 85$ years.

In contrast, no ICU admissions or deaths were reported among persons aged $\leq 19$ years. The United States nationally is in the initiation phase of the pandemic. States in which community spread is occurring are in the acceleration phase. The duration and severity of each pandemic phase can vary depending on the characteristics of the virus and the public health response. Similar to reports from other countries, this finding suggests that the risk for serious disease and death from COVID-19 is higher in older age groups.

\section{Spread out of SARS-nCoV-2 (COVID-19) in Bangladesh}

A number of news were published and broadcast in Bangladesh since January 2020 as Wuhan was detected the center of Novel Coronavirus. It was a substance of religious belief till the end of January. Most of the people in Bangladesh believed that the virus got mass in China due to non-Muslim (Haram) food habit and people of Bangladesh will not suffer with this Covid-19 issue. In the first week of February, while the virus was taking place to blowout in other states of China as well as the number of infected people were drastically increasing in Wuhan, China and also reported in many countries of the world. Students in the Universities in Wuhan were recalled by the government of Bangladesh and sent to the government provided quarantine shelter for a couple of week. 


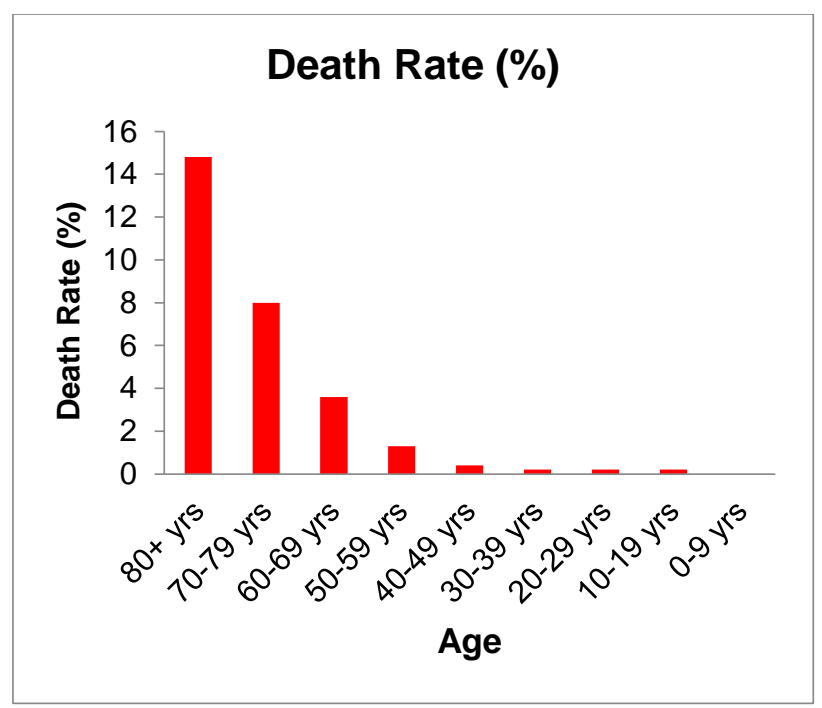

Figure Ia: Global fatality rate of SARS-nCoV-2 (COVID-19 pandemic) by age group

Until the end of February it was not alarming in mass level but only to the civil society. But the bell rang in the public when at the beginning of March, Italy started to suffer and by the end of first week it spread at regional level. As a number of Bangladesh students and workers live in Italy and Germany, the panic started when thousands were coming back to Bangladesh on daily several flights.

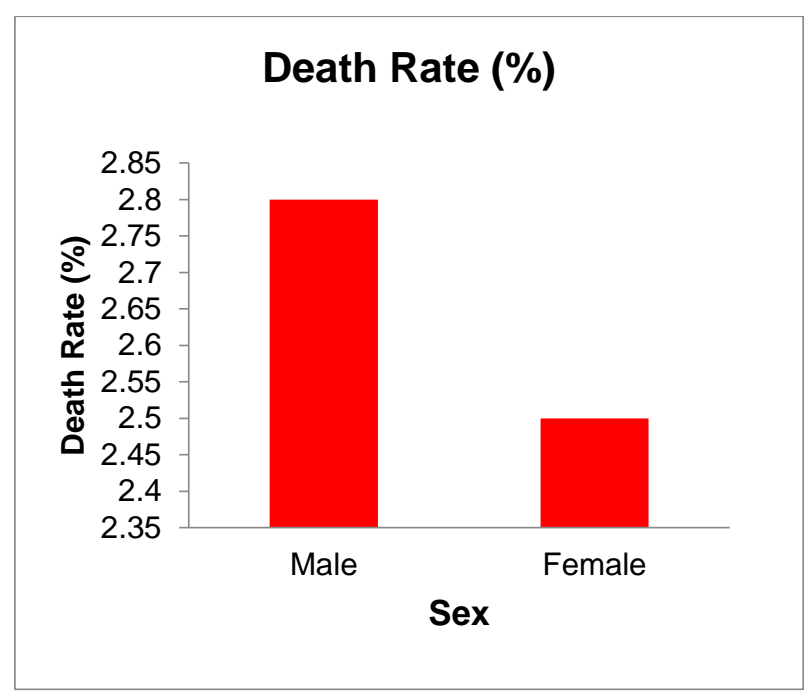

Figure Ib: Global fatality rate of SARS-nCoV-2 (COVID-19 pandemic) by sex

In the face of protests from the expatriates, the government allowed them to cross the immigration with a letter for home quarantine to individuals. Bangladesh confirmed first three cases of coronavirus disease (Covid-19) on March 8, after that Covid-19 cases were increased day by day ${ }^{6}$.
Despite the fact, the expats were not maintaining the home quarantine rule and even some of them arranged their marriage ceremony and some of them went to attend this type of public events. After that, the government of the People's Republic of Bangladesh declared a ban from all the European flights even with transits will be banned to enter Bangladesh from March 16, 2020. Only United Kingdom was an exception in this list as the number of affected in UK was low-slung. This declaration came because of the two coronavirus positive cases among the returning expatriates from Italy and Germany respectively. The primary flight cancellation date was March 31, 2020 but later the government extended until the next announcement. It was a matter of time, as people were expecting a lockdown or public movement control followed by the neighbor India. Bangladesh declared a complete lockdown on March 24, 2020 until April 4. Meanwhile, the number of infected people was risen to 39 when Bangladesh went to the third stage of the Covid-19 attack. By the end of first week, the virus proliferated at community level with its fourth level attack, Bangladesh declared a lockdown until April 25, 2020 and all the educational institutes will remain close until Eid or end of May. The current situation in Bangladesh as of the end of $3^{\text {rd }}$ week of April 2020, the virus is in its fourth stage. On 21 April 2020, approximately 3,382 confirmed cases of coronavirus disease 2019 (COVID-19 pandemic) have been reported in Bangladesh, including an estimated 110 deaths from 64 districts of the country $^{2}$. According to existing data the present fatality rate of SARS-nCoV-2 (COVID-19 pandemic) is $\cong 3.25 \%$. The severity is higher in capital city Dhaka and in nearest districts; Narayanganj, Gazipur, Narshingdi. These districts are identified as hotspots. The fatality rate by age group and $\operatorname{sex}^{6}$. The distribution of confirmed cases were analyzed and it was revealed that the percent disease severity is higher in aged group 21-30 year old followed by 31-40, 40-50 and 50-60 year old. The disease severity in $\geq 60$ year aged people is $10 \%$ and the lowest disease severity was recorded in $\leq 20$ years aged people. It was also reported that the percent disease severity is higher in male $(\cong 70 \%)$ as compere to female (Figure IIa\&b).

In the case of Bangladesh, we can find some of the incident those triggered the negligence towards the impact of Covid-19 in Bangladesh. First of all, this pandemic was a social media troll at the beginning phase. During the first wave, social media trolling went viral and it was a fun fact in the country. At its second phase, when the country had its first positive case, people couldn't have the idea of its impact in next few days. The government was yet to dispatch 
the border control units strictly and people around the world, especially form European countries like Italy, French, Spain, had a direct access to Bangladesh. People were requested to go to the home quarantine system but it was backfired. The homecoming Bangladeshis organized several social gatherings and even at the weddings where others got infected by the virus. Many people were not aware about the situation and they refused to go for selfisolation despite the order from the Ministry of Home Affairs, Bangladesh.

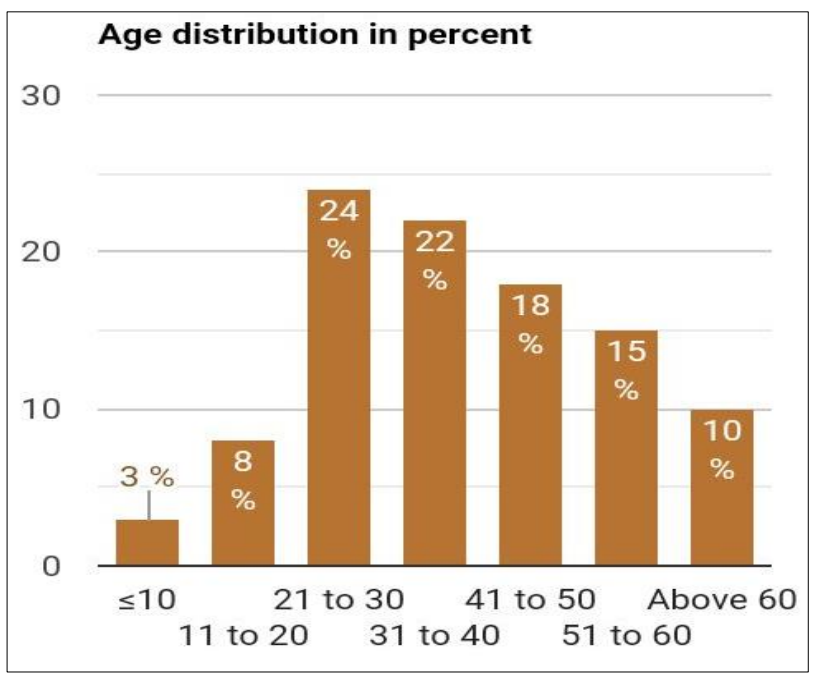

Figure IIa: The disease severity (\%) of SARSnCoV-2 (COVID-19 pandemic) in Bangladesh by age group

People took time to realize the vulnerability of the pandemic and didn't care about the situation at all until the end of March. Prayer at mosques were still public, markets were crowded with people and public transports were used to transport people around the country despite the order of general holiday. Many rumors and fake news were published in this time period in social media. Most of them false claimed to have the cure of Coronavirus as non-medical people. Later, government took strong steps to stop these hoax, but by the time a majority of people had gone through the unexpected hazards. The government took time to announce the lockdown, as the aftermath people treated the situation as general holiday. So people went decentralized and due to general holiday, people went to their hometown leaving the capital Dhaka. By this time, a group of young generation started trolling on social media regarding the Covid19 issue, the virus went to the third phase. After the fourth stage broke up in second week of April, people started to panic and some of the youngsters started to organize relief work. On the other hand, government also stated relief funds and started to distribute via local authority.

\section{Sex distribution in perent}

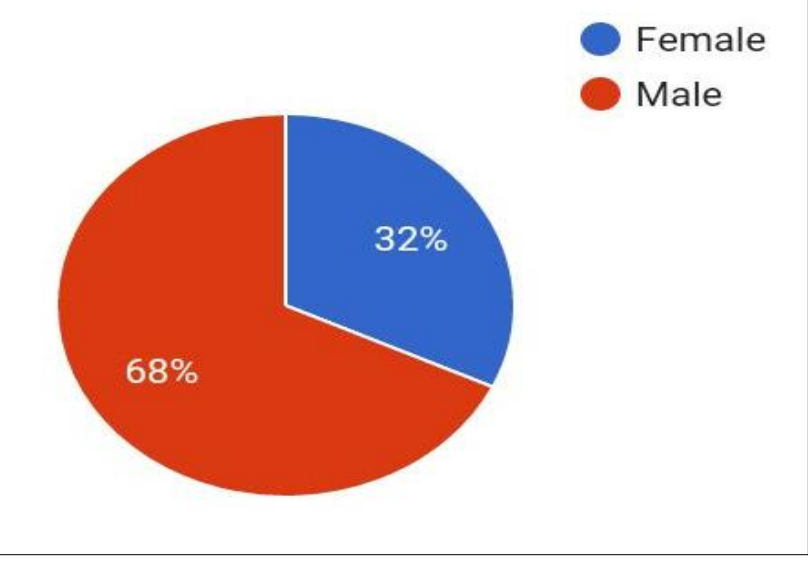

Figure IIb: The disease severity (\%) of SARSnCoV-2 (COVID-19 pandemic) in Bangladesh by sex

\section{References}

1. Moore JC. The History of the Smallpox. London, 1815: Longman.

2. Arpin N, Talbot PJ. Molecular characterization of the 229E strain of human coronavirus. Adv. Exp. Med. Biol. 1990; 276:7380.

3. Tang XC, Agnihothram SS, Jiao Y, Stanhope J, Graham RL, Peterson EC, Avnir Y, Tallarico AS, Sheehan J, Zhu Q. et al. Identification of human neutralizing antibodies against MERS$\mathrm{CoV}$ and their role in virus adaptive evolution. Proc. Natl. Acad. Sci. USA. 2014; 111: E2018-E2026.

4. de Groot RJ, Baker SC, Baric R, Enjuanes L, Gorbalenya AE, Holmes KV., Perlman S, Poon L, Rottier PJM, Talbot PJ, Woo PCY, Ziebuhr J. Coronaviridae. In: King AMQ, Adams MJ, Carstens EB, Lefkowitz EJ (Eds.). Virus Taxonomy: Ninth Report of the International Committee on Taxonomy of Viruses. Elsevier Academic Press, San Diego, 2011:774-796.

5. The World Health Organization (WHO). Coronavirus disease (COVID-19) situation reports, 2020

6. News Links: https://www.weforum.org/agenda/2020/04/inbangladesh-covid-19-could-cause-a-humanitariancrisis/;https://www.worldbank.org/en/news/press release/2020/04/12/bangladesh-must-act-now-to-lessen-covid19-health-impacts 